\title{
Clarificação de Águas Pluviais Ricas em Óxidos de Ferro Acumuladas em Cava de Mineração - Utilização do Coagulante Natural Moringa oleifera
}

\author{
Renalda Monteiro Carvalho, José Fernando de Paiva, Claudia Dumans Guedes \\ Departamento de Quimica - Universidade Federal de Ouro Preto \\ renalda@iceb.ufop.br
}

Recebido: 03/11/05 - revisado: 09/12/05 - aceito: 17/03/06

RESUMO

O problema da clarificação de águas turvas ricas em partículas de óxidos de ferro é abordado neste trabalho, avaliando-se a utilização de um agente coagulante natural - a Moringa oleifera. A adição de $800 \mathrm{mg} / \mathrm{L}$ de um extrato aquoso, preparado utilizando-se 0,5\% em peso de semente, provoca a diminuição da turbidez (20.800 para 80 NTU) da água pluvial acumulada em uma cava de mineração. Embora as concentrações de sódio, potássio, cálcio e magnésio apresentem um aumento considerável com o tratamento, a descarga da água tratada nos cursos de água adjacentes é acompanhada de uma diluição tal que estes teores adquirem valores compatíveis com os limites exigidos pela legislação brasileira. O extrato de moringa não mobiliza ferro a partir das partículas em suspensão, ao contrário do processo de clarificação que é normalmente utilizado e que emprega um agente coagulante e outro floculante. O uso do extrato provoca a diminuição das concentrações de ferro e manganês na água, conforme demonstram os resultados das análises químicas.

Palavras-chave:: turbidez, coagulação-floculação, Moringa oleifera.

\section{INTRODUÇÃO}

As águas naturais, em geral, podem conter uma grande variedade de impurezas suspensas, destacando-se entre elas partículas coloidais de substâncias orgânicas e inorgânicas, substâncias húmicas e microorganismos. Partículas suspensas em águas naturais constituem veículos de transporte de contaminantes orgânicos e inorgânicos, de compostos responsáveis pelo sabor, odor e coloração, e de agentes microbianos patogênicos (Raghuwanshi et al. 2002). A remoção deste material particulado suspenso nas operações de tratamento é, portanto de extrema importância, e a isto se deve o rigor dos padrões de turbidez exigidos para água de consumo humano (Ministério da Saúde 2004).

A região do Quadrilátero Ferrífero, MG, possui grandes reservas minerais, caracterizando-se por uma intensa atividade mineradora, sobretudo de minérios de ferro. A disposição natural das jazidas torna muitas vezes obrigatória a construção de cavas de lavra a céu aberto, dotadas de taludes de contenção dos seus entornos. Estas cavas acabam por se tornar verdadeiros reservatórios de águas pluviais, que escoam através destes mesmos taludes. Estas possuem elevada turbidez e coloração averme- lhada, sendo as partículas em suspensão basicamente constituídas de minerais de ferro. Para a continuidade das atividades de mineração no local é necessário que se retire esta água, a qual normalmente é bombeada e despejada em córregos e rios. Um destes casos é o de empresas mineradoras existentes na região de Ouro Preto e Mariana. Em uma delas, caso que será aqui abordado, a água de uma cava é bombeada para um córrego denominado córrego João Manoel, afluente do rio Piracicaba, que por sua vez faz parte da bacia hidrográfica do Rio Doce (Figura $1)$.

Além dos problemas já mencionados anteriormente e da intensificação dos processos de assoreamento, o transporte de sedimentos constituídos de minerais de efetivo potencial tóxico e sua deposição nos fundos dos rios e nas planícies de sedimentação por ocasião de períodos chuvosos, pode favorecer eventualmente a biodisponibilização destes elementos. Fatores como a presença de matéria orgânica e o pH favorecem a mobilização dos elementos tornando-os disponíveis na forma dissolvida (Ross e Bartlett 1996; Alvarez et al. 1992).

Em áreas de mineração o restabelecimento da cobertura vegetal é o único recurso que pode efetivamente controlar a erosão, e consequentemente a mobilização e sedimentação de minerais. Mas este restabelecimento é conseguido geralmente em 
longo prazo e a necessidade de controle dos efeitos gerados por estes processos requer também medidas imediatas para se evitar maiores alterações nas características dos cursos d'água. Igualmente nos casos de bombeamento de águas turvas para liberar locais a serem minerados, o tratamento prévio destas águas é recomendado, antes de descarregá-las nos córregos e rios.

Os coagulantes químicos mais empregados no tratamento de águas turvas são os sais de alumínio: $\mathrm{Al}_{2}\left(\mathrm{SO}_{4}\right)_{3}$ (alúmen), o WAC (cloro-sulfato de alumínio parcialmente hidrolisado) e o PAC (policloreto básico de alumínio). O emprego destes compostos pode aumentar a concentração de alumínio dissolvido no produto final e também aumentar a acidez do meio, em virtude dos processos de hidrólise envolvidos (Guedes et al. 2004). O alumínio dissolvido na água tratada pode produzir efeitos danosos em seres vivos. A sua relação com a incidência do mal de Alzheimer em seres humanos (Martyn et al. 1989), e outras enfermidades tais como demência, alterações na coordenação motora, mal de Parkinson e síndrome de Down (Freitas 1997), tem despertado a iniciativa de pesquisadores em busca de compostos alternativos de efeito coagulante satisfatório, e menos danosos à saúde humana e ao meio ambiente.

A Moringa oleifera é uma planta pertencente à família Moringaceae e tem sido utilizada como coagulante natural em diferentes países dos continentes asiático, africano e sul-americano (Jahn et al. 1986). O extrato aquoso das sementes descascadas constitui um coagulante ou auxiliar de coagulação que, no Sudão, é empregado em substituição ao alúmen no tratamento das águas argilosas de alta turbidez - 3000 a 8000 NTU, do rio Nilo Azul (Jahn e Dirar 1979). Alguns estudos já foram realizados utilizando extratos aquosos como coagulantes de suspensões aquosas sintéticas de caulinita (Gassenschmidt et al. 1995; Muyibi e Evision 1995; Ndabigengesere e Narasiah 1998a,b; Okuda et al. 1999; McConnachie et al. 1999). Em suspensões com turbidez inicial elevada (5000NTU) o extrato aquoso mostrou-se eficaz. O mecanismo de coagulação proposto nestes casos consiste na adsorção do agente coagulante contido no extrato sobre as partículas da dispersão, e conseqüente neutralização das suas cargas superficiais.

As vantagens da utilização deste coagulante são várias, e entre elas está o fato de que o volume do lodo gerado é cerca de cinco vezes menor do que o produzido por tratamentos empregando sulfato de alumínio, tendo ainda a vantagem de ser biodegradável (Ndabigengesere et al. 1995; Ndabigenge- sere e Narasiah 1998a). A utilização unicamente do extrato, sem a adição de qualquer outro coagulante auxiliar ou floculante, implica na eliminação da turbidez dentro de uma a duas horas, mantendo-se esta eficiência em ampla faixa de pH. Há de se lembrar que o sulfato de alumínio atua com eficiência em uma faixa restrita de $\mathrm{pH}$ (Guedes 2004).

$\mathrm{O}$ tratamento de água turva com as sementes da Moringa oleifera ainda possui efeito biológico, permitindo a eliminação de microorganismos patogênicos por sedimentação, pois grande parte destes estão ligados às partículas em suspensão (Olsen 1987)

No caso aqui considerado o bombeamento da água da cava para o córrego causa o aumento na turbidez das suas águas. Dados relativos ao monitoramento diário das águas do córrego João Manoel durante o período da seca, obtidos pela própria empresa que opera na região, mostraram que o valor médio ao longo deste período foi de 108NTU. O tratamento de clarificação é feito no próprio leito do córrego, em um local onde o mesmo já recebeu as águas bombeadas da cava. Neste local é adicionado um agente coagulante - denominado comercialmente como SK $800^{\circledR}$ - seguido da adição de um floculante - o Mafloc BG $100^{\circledR}$.

O coagulante SK $800^{\circledR}$ e uma mistura de polímeros catiônicos inorgânicos (sais inorgânicos) e orgânicos. Este agente é eficaz quando o pH da água encontra-se entre 6,5 e 7,0. Eventualmente ocorre que o pH encontra-se abaixo de 6,5. Nestas ocasiões há a necessidade de um ajuste prévio, o que é feito através da adição de óxido de cálcio $(\mathrm{CaO})$ ou de hidróxido de sódio $(\mathrm{NaOH})$. O floculante auxiliar possui em sua composição polímeros aniônicos e sal de sódio.

Este trabalho procurou realizar a caracterização físico-química das águas, a avaliação dos desempenhos do tratamento normalmente utilizado e dos extratos de semente da Moringa oleifera na coagulação das partículas em suspensão, e a qualidade do produto final, neste caso a água pluvial acumulada em cava de lavra de exploração de minério de ferro.

\section{METODOLOGIA}

As amostras de águas foram coletadas e armazenadas de acordo com os procedimentos sugeridos por normas estabelecidas em Agudo (1987). Os locais de amostragem estão apresentados na Figura 1. 


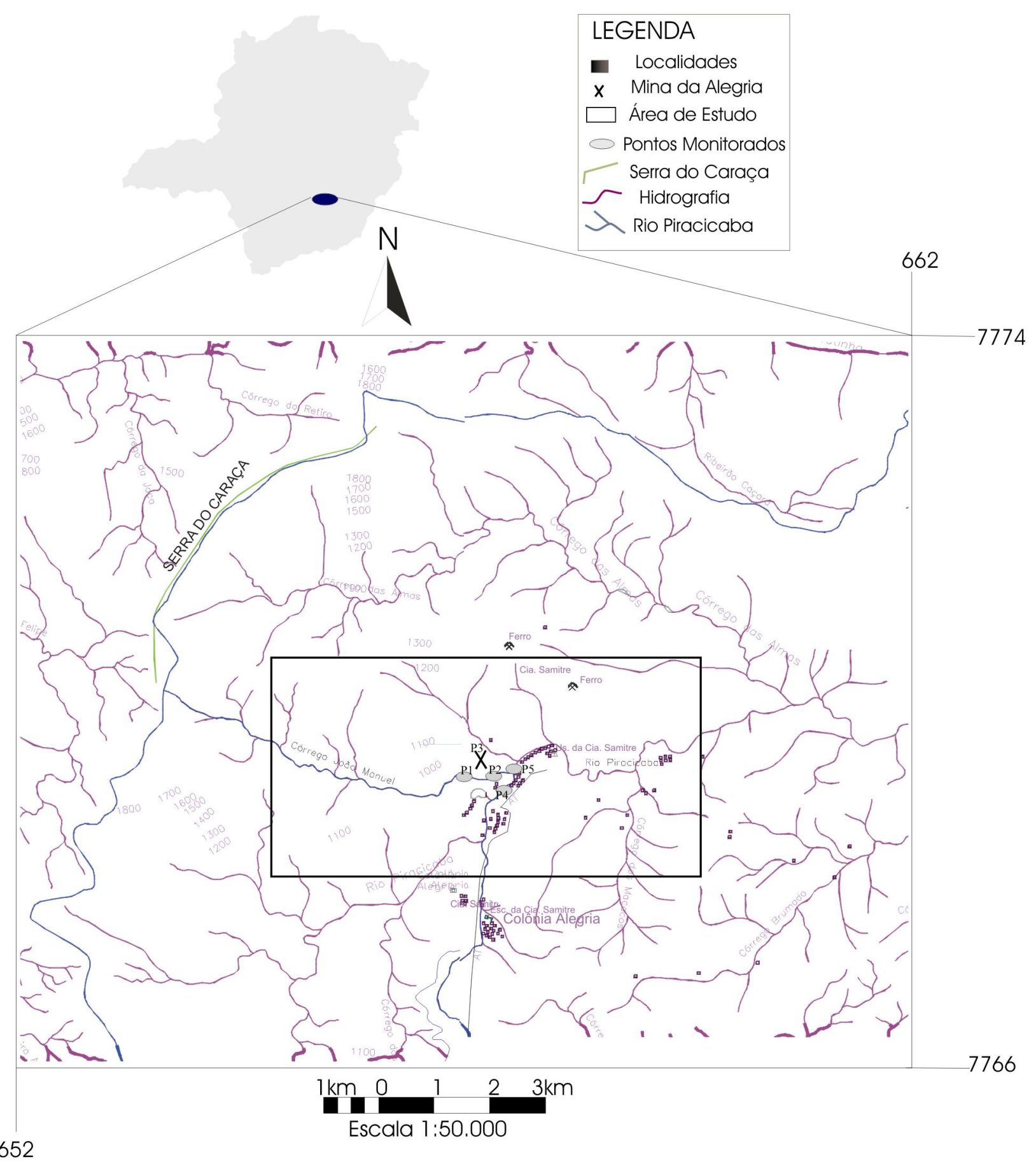

Figura 1 - Localização e pontos de amostragem na região do córrego João Manoel e do rio Piracicaba. 
A amostragem foi realizada em junho/2004, período este onde ocorre efetivamente o bombeamento da água da cava para o córrego mencionado anteriormente. Os parâmetros condutividade, Eh, $\mathrm{pH}$ e temperatura foram medidos no próprio local da amostragem, utilizando-se um medidor multiparâmetros da marca MYRON L COMPANY modelo Ultrameter 6P. No mesmo dia da coleta foram determinados a intensidade da cor, o teor de sólidos totais e turbidez em um Fotômetro MERCK modelo SQ118.

O teor de cloreto foi determinado pelo método titulométrico (Adad 1983) e a demanda química de oxigênio pelo método do dicromato, refluxo fechado (Greenberg et al. 1992). Para tal a amostra foi previamente filtrada a vácuo em membrana de celulose de $0,45 \mu \mathrm{m}$ de diâmetro de poro. Uma fração da mesma foi submetida à análise química por Espectrofotometria de Emissão Atômica com Fonte de Plasma Indutivamente Acoplado(ICP-AES) em um aparelho da marca SPECTRO modelo Ciros CCD.

A proporção de sólidos suspensos presentes foi determinada por evaporação da fração líquida, e a fração sólida foi caracterizada quanto à composição química por ICP-AES no equipamento já mencionado. Foi realizada também a determinação da composição mineralógica por Difração de Raios-X em um difratômetro SHIMADZU modelo XRD 6000, com tubo de cobalto, pelo método do pó.

A Moringa oleifera foi utilizada na clarificação da água pluvial acumulada na cava através do preparo de extratos aquosos das sementes. Estas foram descascadas imediatamente antes de serem utilizadas. Apenas os grãos descascados aparentemente perfeitos foram selecionados, triturados em almofariz, pesados e misturados com água destilada e deionizada para constituir extratos aquosos de concentrações $0,5 \%, 1,0 \%$, e $10,0 \% \mathrm{~m} / \mathrm{v}$. Estas misturas foram agitadas durante $5 \mathrm{~min}$ e em seguida deixadas em repouso por $150 \mathrm{~min}$. Logo após as mesmas foram filtradas a vácuo em membrana de celulose com $0,45 \mu \mathrm{m}$ de diâmetro de poro. Estes extratos foram utilizados em ensaios de clarificação (Jar-test MILAN modelo JT 101) em seis recipientes contendo $100 \mathrm{~mL}$ de amostra de água turva, variando-se as dosagens dos extratos adicionados nos recipientes. Após as adições era feita em cada recipiente uma agitação em 120rpm durante $3 \mathrm{~min}$, seguida de agitação em $40 \mathrm{rpm}$ durante $30 \mathrm{~min}$ e finalmente um repouso de 30min. No final recolhia-se o sobrenadante de cada recipiente para a determinação da turbidez final.

\section{RESULTADOS}

As análises físico-químicas das águas da cava de mineração (P3), de um local próximo à nascente do córrego (P1), de um local no córrego após o mesmo ter recebido a descarga de águas da cava (P2), do rio Piracicaba a montante (P4) e a jusante (P5) da foz do córrego, forneceram os resultados apresentados na tabela 1 .

Tabela 1 - Parâmetros físico-químicos da água acumulada na cava de lavra, da água do córrego e da água do rio.

\begin{tabular}{||l|l|l|l|l|l||}
\hline \multirow{2}{*}{ Parâmetros } & \multicolumn{5}{|l||}{ Medidas nas várias amostras } \\
\cline { 2 - 6 } & P1 & P2 & P3 & P4 & P5 \\
\hline Alcalinidade $(\mathrm{mg} / \mathrm{L})$ & 3,9 & 11,8 & - & 5,9 & 6,7 \\
\hline Cloreto $(\mathrm{mg} / \mathrm{L})$ & 2,0 & 3,2 & 1,7 & 2,5 & 3,0 \\
\hline Condutiv. $(\mu \mathrm{S} / \mathrm{cm})$ & 4,6 & 43,0 & 22,2 & 9,8 & 15,1 \\
\hline Cor $($ Hazen $)$ & 10 & 58 & - & 14 & 25 \\
\hline DQO $(\mathrm{mg} / \mathrm{L})$ & $<5$ & $<5$ & $<5$ & $<5$ & $<5$ \\
\hline Eh $(\mathrm{mV})$ & 135 & 50 & 176 & 207 & 149 \\
\hline pH & 5,6 & 5,8 & 5,6 & 5,9 & 6,6 \\
\hline S. suspensos $(\mathrm{mg} / \mathrm{L})$ & 2,0 & 22,0 & 1464,0 & 4,0 & 8,0 \\
\hline S. totais $(\mathrm{mg} / \mathrm{L})$ & 3,1 & 30,7 & 3024,0 & 6,3 & 9,8 \\
\hline Temperatura $(\mathrm{C})$ & 15,7 & 17,5 & 19,4 & 18,2 & 19,5 \\
\hline Turbidez $(\mathrm{NTU})$ & 2 & 60 & 20800 & 8 & 18 \\
\hline \hline
\end{tabular}

A amostra coletada no córrego João Manoel pode ser considerada como o background do sistema hídrico em estudo. Os valores das medidas de seus parâmetros podem ser atribuídos às características do solo e de rochas da região que entram em contato com a água, desde onde a mesma constitui o lençol freático até o ponto de amostragem P1.

A amostra P2 corresponde ao ponto de amostragem onde o córrego João Manoel já havia recebido a contribuição da água da cava, e também já havia sofrido o tratamento de clarificação. Verifica-se que em relação à amostra $\mathrm{P} 1$, houve alterações na maioria dos parâmetros analisados. Ocorreram aumentos consideráveis na alcalinidade, na condutividade, na intensidade da cor, no teor de sólidos suspensos e totais, e na turbidez. Nestes quatro últimos parâmetros, os aumentos evidentemente estão relacionados com a contribuição da água da cava. Quanto à alcalinidade e à condutividade, provavelmente os aumentos devem-se aos resíduos químicos provenientes dos agentes coagulante e floculante 
adicionados. Os ligeiros aumentos nos teores de cloreto e de sólidos dissolvidos (diferença entre sólidos totais e sólidos suspensos) devem-se provavelmente também aos resíduos dos aditivos de tratamento. Como a água da amostra P1 possui nesta ocasião pH abaixo de 6,5, e nestas condições o agente coagulante utilizado não possui efeito satisfatório, adições de cal foram realizadas, e isto explica o valor de $\mathrm{pH}$ ligeiramente mais elevado da amostra P2. Quanto aos valores de DQO observa-se que, mesmo com as adições de coagulante e floculante, não houve aumento detectável de carga orgânica na água. Certamente que a incorporação destes aditivos ao sólido decantado ao longo do leito do rio, além de efeitos de diluição, contribuiu para este resultado. Há de se observar ainda que houve uma diminuição considerável do valor do Eh da amostra P1 para a amostra P2, indicando um aumento no caráter redutor do meio. Levando-se em conta a diluição que ocorre com a água da cava ao ser descarregada no córrego, tanto o valor relativamente mais elevado de $\mathrm{pH}$ quanto o valor mais baixo do Eh que ocorrem na amostra P2, apenas podem ser explicados como devidos às adições de cal, coagulante e floculante no processo de clarificação.

Os resultados para a amostra P3 fornecem as características da água da cava. Esta possui valores elevados de sólidos totais e de sólidos suspensos, e coerentemente, uma turbidez extremamente elevada. Os valores de condutividade e de sólidos dissolvidos são bem mais elevados que os da água do córrego em P1, ficando evidente que o aumento observado destes parâmetros na amostra $\mathrm{P} 2$, deve-se, entre outras, à contribuição da água da cava. No que se refere ao valor do $\mathrm{pH}$, verifica-se que neste aspecto a água que se acumula na cava não é diferente da água típica do córrego. Devido a grande presença de sólidos suspensos na água da cava não foi possível quantificar os parâmetros alcalinidade e cor.

Conforme mencionado anteriormente, ao ser bombeada até o córrego a água da cava causa o aumento da sua turbidez de 2 para cerca de 108NTU, em média. Assim, ao sofrer tratamento de clarificação, a turbidez diminui para 60NTU. Mesmo com este tratamento os efeitos do despejo da água da cava são ainda percebidos no rio Piracicaba, como se pode observar pelos dados da amostra P5.

Os resultados para a amostra $\mathrm{P} 4$ são típicos para águas do rio Piracicaba antes deste receber as águas do córrego João Manoel. Em comparação com a amostra P1 verificam-se, em geral, ligeiros aumentos em todos os parâmetros físico-químicos analisados. Estes podem ser atribuídos às descargas de esgotos e tributários que chegam ao rio antes do referido ponto.

As águas da região foram também caracterizadas quimicamente por Espectrofotometria de Emissão Atômica com Fonte de Plasma Indutivamente Acoplado (ICP-AES). Os resultados obtidos para os metais que foram detectados são apresentados na tabela 2 .

Tabela 2 - Resultados obtidos por análise de ICP-AES, para as amostras de água do córrego, do rio e da cava.

\begin{tabular}{||l|l|l|l|l|l||}
\hline \multirow{2}{*}{ Elementos } & \multicolumn{5}{|c||}{ Medidas nas várias amostras } \\
\cline { 2 - 6 } & P1 & P2 & P3 & P4 & P5 \\
\hline Alumínio $(\mu \mathrm{g} / \mathrm{L})$ & 22 & 42 & $<4$ & 10 & 12 \\
\hline Bário $(\mu \mathrm{g} / \mathrm{L})$ & 2 & 22 & 23 & 20 & 11 \\
\hline Cálcio $(\mu \mathrm{g} / \mathrm{L})$ & 96 & 884 & 217 & 680 & 759 \\
\hline Ferro $(\mu \mathrm{g} / \mathrm{L})$ & 53 & 733 & 33 & 109 & 102 \\
\hline Magnésio $(\mu \mathrm{g} / \mathrm{L})$ & 62 & 93 & 11 & 170 & 163 \\
\hline Manganês $(\mu \mathrm{g} / \mathrm{L})$ & 8 & 572 & 330 & 269 & 295 \\
\hline Potássio $(\mu \mathrm{g} / \mathrm{L})$ & 64 & 301 & 167 & 982 & 1456 \\
\hline Sódio $(\mu \mathrm{g} / \mathrm{L})$ & 150 & 4033 & 622 & 515 & 982 \\
\hline \hline
\end{tabular}

Novamente aqui se observa teores mais elevados de praticamente todos os metais para a água do rio Piracicaba em relação à água do córrego, isto é provavelmente devido às descargas recebidas pelo rio até o local de coleta da amostra $\mathrm{P} 4$. Em relação à amostra P2 verifica-se um grande aumento nos teores quando comparados aos da amostra P1. Estes aumentos, em geral, podem ser atribuídos às descargas de água da cava e às adições de coagulante, floculante e corretores de $\mathrm{pH}$, ao córrego João Manoel. Com efeito, o grande aumento no teor de cálcio e a elevação de $\mathrm{pH}$ mostrada na tabela 2 , são indícios de efeitos da adição de cal. O extraordinário aumento no teor de sódio é uma conseqüência da adição do floculante, que possui um sal de sódio na sua composição. No que se refere aos aumentos nas concentrações de ferro e de manganês, há de se observar que estes ocorrem com a diminuição simultânea do Eh do meio. A ocorrência de valores relativamente mais baixos de Eh favorece a formação de espécies metálicas em estados de oxidação mais baixos e predominantemente mais solúveis, conforme sugere os diagramas Eh-pH para o ferro e para o manganês (Pourbaix 1963).

Tendo em vista que os teores de alguns elementos na amostra P3 são menores que os da amostra P2, e levando-se em conta que, além disso, 
ainda ocorre a diluição da água da cava, não é razoável admitir que os teores na amostra P2 sejam devidos aos sólidos dissolvidos presentes na água da cava. $\mathrm{O}$ aumento intenso nos teores de metais na amostra P2 em relação à amostra P1 indica que provavelmente houve algum processo de dissolução de minerais ao se passar de um ponto a outro no córrego. Pode-se observar um aumento da concentração de ferro de 53 para $733 \mu \mathrm{g} / \mathrm{L}$, a de alumínio de 22 para $42 \mu \mathrm{g} / \mathrm{L}$, a de manganês de 8 para $572 \mu \mathrm{g} / \mathrm{L}$, a de bário de 2 para $22 \mu \mathrm{g} / \mathrm{L}$, o magnésio de 62 para $93 \mu \mathrm{g} / \mathrm{L}$, e o de potássio de 64 para $301 \mu \mathrm{g} / \mathrm{L}$. Conforme mencionado anteriormente, a diminuição simultânea no valor do Eh é coerente com estes aumentos de concentração.

Levando-se em conta que a água da cava ao ser descarregada no córrego sofre diluição, e tendo em vista os teores dos metais presentes na mesma, pode-se considerar que, sob o ponto de vista de substâncias dissolvidas, esta operação não causa danos ao rio.

A figura 2 apresenta o difratograma de Raios-X para as partículas em suspensão na água da cava.

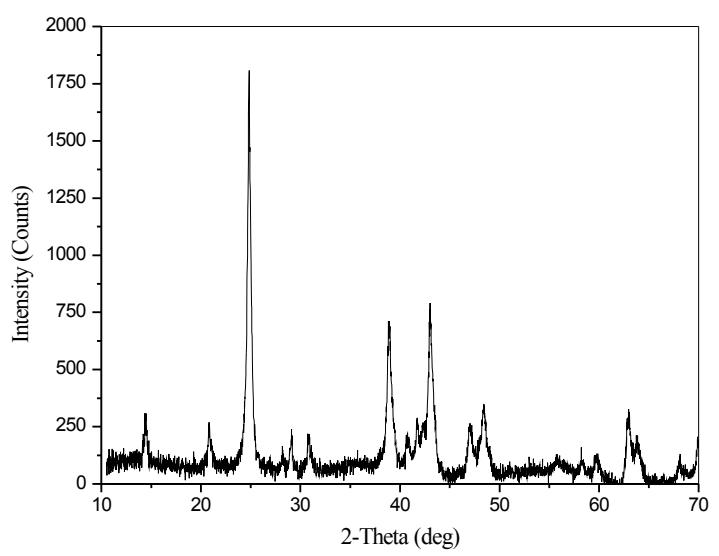

Figura 2 - Difratograma de Raios-X da fração sólida da água da cava.

Podem-se observar picos em aproximadamente 14, 29, 41 e 42 graus, os quais correspondem à Caulinita $\left[\mathrm{Al}_{2} \mathrm{Si}_{2} \mathrm{O}_{5}(\mathrm{OH})_{4}\right]$. Os picos em 25, 39, 43, 47,48 e 63 graus correspondem à Goethita [Fe$\mathrm{O}(\mathrm{OH})]$. Os picos em 39, 42, 58 e 64 graus correspondem à Hematita $\left(\mathrm{Fe}_{2} \mathrm{O}_{3}\right)$. As reflexões características dos planos atômicos que identificam os minerais foram comparados com cartões padrão da
JCPDF, 29-1488 para a Caulinita, 29-0713 para a Goethita e 33-0664 para a Hematita. Estes são, portanto minerais predominantes nas partículas sólidas em suspensão na água da cava.

A análise química da fração sólida presente na água da cava forneceu os resultados apresentados na tabela 3 .

Tabela 3 - Resultados obtidos por análise de ICP-AES para a fração sólida presente na água da cava.

\begin{tabular}{|l|c|c|c||}
\hline Elemento & $\begin{array}{c}\text { Teor } \\
(\boldsymbol{\mu g} / \mathbf{g})\end{array}$ & Elemento & $\begin{array}{c}\text { Teor } \\
(\boldsymbol{\mu g} / \mathbf{g})\end{array}$ \\
\hline Ferro & 552.418 & Cálcio & 78 \\
\hline Alumínio & 30.959 & Cádmio & 47 \\
\hline Titânio & 3.463 & Cromo & 44 \\
\hline Fósforo & 2.450 & Bário & 38 \\
\hline Manganês & 1.745 & Bismuto & 24 \\
\hline Enxofre & 824 & Ítrio & 22 \\
\hline Magnésio & 356 & Tório & 19 \\
\hline Sódio & 151 & Estrôncio & 14 \\
\hline Chumbo & 145 & Escândio & 11 \\
\hline Zircônio & 141 & Cobalto & 10 \\
\hline Vanádio & 121 & Cobre & 9 \\
\hline Potássio & 93 & Níquel & 5 \\
\hline Zinco & 81 & Lítio & 0,4 \\
\hline \hline
\end{tabular}

Coerentemente com o resultado obtido pela análise por Difração de Raios-X, verificaram-se como principais elementos presentes o ferro e o alumínio.

Por tudo isto então, a presença de cálcio, sódio e potássio, na água clarificada (amostra P2) apenas pode ser atribuída às adições de corretor de $\mathrm{pH}$, coagulante e floculante, já que na composição mineralógica e química da fração sólida da água da cava não foram detectadas quantidades consideráveis destes elementos. Quanto ao ferro e ao manganês presentes em P2, estes efetivamente devem ter se originado da água da cava.

A figura 3 mostra os resultados para a redução da turbidez de amostras de água da cava, obtidos após séries de Jar-test, onde foram variadas as dosagens de coagulantes. Foram utilizados como coagulantes extratos de sementes em três concentrações, a saber, 0,$5 ; 1,0$ e $10,0 \% \mathrm{~m} / \mathrm{v}$. As concentrações a que se referem a figura correspondem à massa de semente nos ensaios de Jar-test, resultantes de adições de volumes destes extratos aos recipientes de ensaios. 


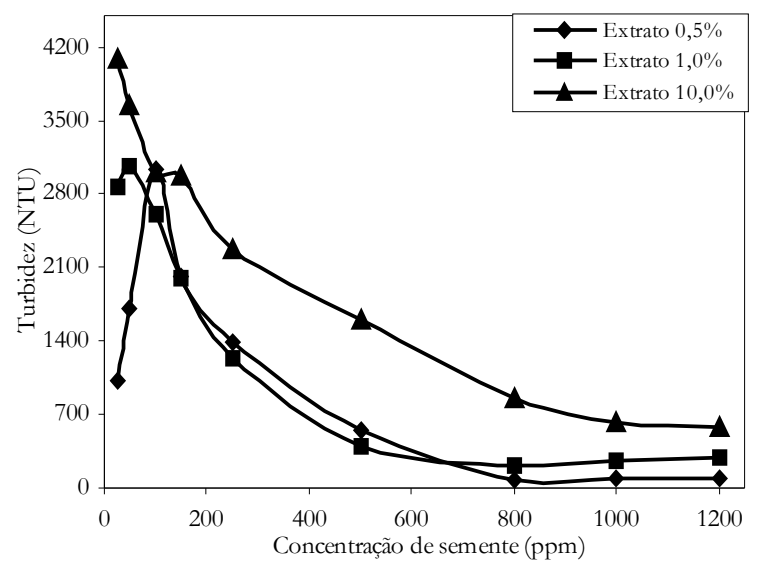

Figura 3 - Turbidez final versus concentrações de semente nos ensaios.

Observa-se que efetivamente os extratos aquosos promovem a clarificação da água, mesmo sem a utilização de um agente floculante auxiliar. A partir de uma turbidez inicial de 20800NTU para a água da cava chega-se a valores de 83, 208 e 852NTU utilizando-se $800 \mathrm{ppm}$ dos extratos a 0,$5 ; 1,0$ e $10,0 \%$ $\mathrm{m} / \mathrm{v}$ respectivamente, nos ensaios de Jar-test. A água da cava ao ser descarregada no córrego João Manoel sofre naturalmente uma grande diluição, quando não há nenhum tratamento a turbidez passa de 20800 para 108NTU. Com o tratamento prévio utilizando o extrato ter-se-ia como ponto de partida para a diluição uma água de turbidez já bem reduzida, e não se espera que sob este aspecto a mesma possa causar ainda interferências no referido córrego.

No caso do ensaio com o extrato a $0,5 \%$ e concentração de $800 \mathrm{ppm}$, a água tratada apresentou $\mathrm{pH}$ igual a 6,3 ; condutividade igual a $53,9 \mu \mathrm{S} / \mathrm{cm}$ e DQO abaixo de $5 \mathrm{mg} / \mathrm{L}$. Processos físico-químicos desencadeados pela adição do extrato provocam um ligeiro aumento no $\mathrm{pH}$ e na condutividade da água da cava. De qualquer forma, conforme mencionado acima, a diluição que ocorre na mistura com a água do córrego deve minimizar estes efeitos sobre a água do córrego. Mesmo sendo o extrato composto de matéria orgânica proveniente da semente, não há aumento na DQO da água da cava devido à adição do mesmo.

A tabela 4 apresenta os resultados de análises feitas por ICP-AES de amostras de água da cava tratadas com três concentrações de semente, adicionadas a partir do extrato a $0,5 \%$. Apenas os elementos detectados estão mostrados na tabela.
Tabela 4 - Teores dos metais maiores nos sobrenadantes de amostras de água da cava de mineração (P3), após tratamento de clarificação por adição de extrato a $0,5 \%$.

\begin{tabular}{||l|c|c|c||}
\hline \multirow{2}{*}{$\begin{array}{l}\text { Elementos/L.Q.* } \\
(\boldsymbol{\mu g} / \mathbf{L})\end{array}$} & \multicolumn{3}{|c||}{$\begin{array}{c}\text { Concentrações de semente } \\
\text { (ppm) }\end{array}$} \\
\cline { 2 - 4 } & $\mathbf{2 5}$ & $\mathbf{8 0 0}$ & $\mathbf{1 0 0 0}$ \\
\hline Cálcio/10 & 220 & 758 & 771 \\
\hline Magnésio/10 & 80 & 1110 & 1230 \\
\hline Manganês/4 & 196 & 160 & 149 \\
\hline Potássio/50 & 1236 & 8640 & 8860 \\
\hline Sódio/150 & 980 & 1280 & 1250 \\
\hline
\end{tabular}

*Limite de quantificação

Efetivamente a adição de extrato provoca aumento nos teores de vários metais na água. Através de resultados de análises químicas estes metais já foram reconhecidos como constituintes metálicos majoritários do extrato aquoso, conforme o trabalho de Ndabigengesere e Narasiah 1998a. Através da variação da turbidez da água da cava ao ser diluída durante o processo de mistura com a água do córrego (de 20800 para 108NTU), faz-se uma estimativa de um fator de diluição de 192, podendo-se estimar que as concentrações dos elementos da tabela 4 no córrego serão bem inferiores às suas concentrações na amostra P2.

\section{CONCLUSÕES}

O bombeamento de águas acumuladas em cavas de mineração com o intuito de desobstruí-las, e o seu despejo em cursos de águas naturais, efetivamente causam aumento na turbidez destas águas. Após o tratamento que é realizado para eliminar esta turbidez, observam-se efeitos deste tratamento nos valores dos parâmetros físico-químicos e na composição química da água tratada. No caso estudado, parte dos efeitos tem origem nas descargas de água da cava e parte tem origem nos resíduos dos agentes clarificantes adicionados. Essencialmente estes agentes contribuem com os aumentos na condutividade, introduzindo ao meio teores consideráveis de cálcio (de 96 para $884 \mu \mathrm{g} / \mathrm{L}$ respectivamente de P1 para P2) e sódio (de 150 para $4033 \mu \mathrm{g} / \mathrm{L}$ respectivamente de $\mathrm{P} 1$ para $\mathrm{P} 2$ ). A água da cava sofre uma diluição intensa ao ser misturada com o córrego, e as contribuições oriundas da composição quí- 
mica da parte dissolvida não são significativas, e, além disso, esta fração não possui características muito distintas da água original do córrego.

Por outro lado, as partículas suspensas além de contribuírem significativamente para a elevação da turbidez (de 2 para 108NTU quando a água do córrego não é tratada, e para 60NTU mesmo havendo o tratamento), também podem causar aumentos nos teores de metais quando a água do córrego é tratada após receber a água da cava, devido a mudanças nas condições físico-químicas ocasionadas pelas adições dos agentes clarificantes, que podem desencadear processos de dissolução. Assim, no caso estudado, quando se leva em consideração os dados das amostras P1 e P2, observa-se que a concentração de ferro aumentou de 53 para $733 \mu \mathrm{g} / \mathrm{L}$, a de alumínio de 22 para $42 \mu \mathrm{g} / \mathrm{L}$, a de manganês de 8 para $572 \mu \mathrm{g} / \mathrm{L}$, a de bário de 2 para $22 \mu \mathrm{g} / \mathrm{L}$, o magnésio de 62 para $93 \mu \mathrm{g} / \mathrm{L}$, e o de potássio de 64 para $301 \mu \mathrm{g} / \mathrm{L}$. De fato estes metais aparecem em teores importantes na composição química da fração sólida da água da cava.

No que se refere à água tratada com o coagulante alternativo, a Moringa oleifera, novamente aqui ocorre um aumento de teores de metais na água tratada, componentes estes provenientes do coagulante. Isto pode ser observado pelo aumento na condutividade (de $22,2 \mu \mathrm{S} / \mathrm{cm}$ na água da cava para $53,9 \mu \mathrm{S} / \mathrm{cm}$ na água da cava tratada), e pelo aumento nos teores de cálcio, magnésio, sódio e potássio, após o tratamento.

No entanto, a adição deste coagulante não parece desencadear processos de dissolução da fração sólida da água da cava. Com efeito, na fração dissolvida (amostra P3 na tabela 2) a concentração de ferro é igual a $33 \mu \mathrm{g} / \mathrm{L}$, e na água clarificada o ferro nem ao menos foi detectado (tabela 4). A propósito, o ferro é o metal predominante na composição das partículas em suspensão na água da cava. Em relação ao manganês, metal importante na composição das partículas em suspensão e originalmente presente de forma muito significativa na fração dissolvida da água da cava $(330 \mu \mathrm{g} / \mathrm{L}$ - amostra P3 na tabela 2), a adição de moringa causa uma diminuição na sua concentração (tabela 4).

\section{REFERÊNCIAS}

ADAD, J.M.T. 1983. Controle químico de qualidade. LTC Livros Técnicos e Científicos Editora. Rio de Janeiro. 204p.
AGUDO, E.G. 1987. Guia de coleta e preservação de amostras de água. CETESB. São Paulo. 150p.

ALVAREZ, E.; MARTINEZ, A.; CALVO R. 1992. Geochemical aspects of aluminum in forest soils in Galicia. Biogeochemistry 16: 167-180.

FREITAS, M.B. 1997. Avaliação da qualidade da água consumida no Parque Fluminense - Duque de Caxias - enfoque para a presença de metais $(\mathrm{Fe}, \mathrm{Mn}, \mathrm{Zn}, \mathrm{Cu}$, $\mathrm{Cr}, \mathrm{Ni}, \mathrm{Cd}$ e Al). Dissertação de Mestrado. Escola Nacional de Saúde Pública/FIOCRUZ. Rio de Janeiro/RJ. 66p.

GASSENSCHMIDT, U.; JANY, K.D.; TAUSCHER, B.; NIEBERGALL, H. 1995. Isolation and characterization of flocculating protein from Moringa oleifera lam. Biochimica et Biophysica Acta 1243: 477-481.

GREENBERG, A.E.; CLESCERI, L.S.; EATON, A.D. 1992. Standard methods for the examination of water and wastewater. 18.ed. Washington: American Public Health Association. 2134p.

GUEDES, C.D. 2004. Coagulação/Floculação de águas superficiais de minerações de ferro com turbidez elevada. Tese de Doutoramento. DEGEO/EM/UFOP. Ouro Preto/MG. 159p.

GUEDES, C. D. PEREIRA, J.G.; LENA, J.C.; PAIVA, J.F. 2004. Coagulação/Floculação de suspensões ricas em óxidos de ferro por sulfato de alumínio. Química Nova 27(5) 715-719.

JAHN, S.A.A.; DIRAR, H. 1979. Studies on natural coagulants in the Sudan, with special reference to Moringa oleifera seeds. Water SA 5(2): 90-97.

JAHN, S.A.A.; MUSNAD, H.A.; BURGSTALLER, H. 1986. The tree that purifies water - Cultivating multipurpose Moringaceae in the Sudan. Unasylsa 152 (38): 2328.

MARTYN, C.N.; BARKER, D.P.H.; OSMOND, C.; HARRIS, E.C.; EDWARDSON, J.L.; LACEY, R.F. 1989. Geographical relation between Alzheimer's disease and aluminum in drinking water. Lancet 1(8629): 59-62.

MCCONNACHIE, G.L.; FOLKARD, G.K.; MTAWALI, M.A.; SUTHERLAND, J.P. 1999. Field trials of appropriate hydraulic flocculation processes. Wat. Res. 33(6): 1425-1434.

MINISTÉRIO DA SAÚDE. 2004. Portaria $n^{0} 518$, de 25 de março de 2004. Estabelece os procedimentos e responsabilidades relativosao controle e vigilância da qualidade da água para consumo humano e seu padrão de potabilidade. Brasil. Disponível em: www.saude.gov.br

MUYIBI, S.A.; EVISION, L.M. 1995. Optimizing physical parameters affecting coagulation of turbid water with Moringa oleifera seeds. Wat. Res. 29(12): 26892695.

NDABIGENGESERE, A.; NARASIAH, K.S.; TALBOT, B.G. 1995. Active agents and mechanism of coagulation 
of turbid waters using Moringa oleifera. Wat. Res. 29 (2): 703-710.

NDABIGENGESERE, A.; NARASIAH, K.S. 1998a. Quality of water treated by coagulation using Moringa oleifera seeds. Wat. Res. 32(3): 781-791.

NDABIGENGESERE, A.; NARASIAH, K.S. 1998b. Use of Moringa oleifera seeds as a primary coagulant in wastewater treatment. Environmental Technology 19(8): 789-800.

OKUDA, T.; BAES, A.U.; NISHIJIMA, W.; OKADA, M. 1999. Improvement of extraction method of coagulation active components from Moringa oleifera seed. Wat. Res. 33(15): 3373-3378.

OLSEN, A. 1987. Low technology water purification by Bentonite Clay and Moringa oleifera seed floculation as performed in Sudanese Villages: Effects on Schistosoma mansoni cercariae. Wat. Res. 21(5): 517-522.

POURBAIX, M. 1963. Atlas d'équilibres électrochimiques. Vol.1. Gauthier-Villars \& Cle Éditeur. Paris/France. 644p.

RAGHUWANSHI, P.K.; MANDLOI, M.; SHARMA, A.J.; MALVYIA, H.; CHAUDHARI, S. 2002. Improving filtrate quality using agrobased materials as coagulant aid. Wat. Qual. Res. J. Canada. 37(4): 745-756.

ROSS. D.S.; BARTLETT, R.J. 1996. Field-extracted spodosol solutions and soils: aluminum, organic carbon and $\mathrm{pH}$ interrelashionships. Soil Science Society of America Journal 60(2): 589-595.

\section{Clarification of Vial Waters Rich In Iron Oxides Accumulated In Open Pit Mining Trenches. Use of The Natural Coagulant Moringa oleifera}

\footnotetext{
ABSTRACT

This study deals with the problem of the clarification of turbid waters rich in iron oxide particles, assessing the use of a natural coagulant - Moringa oleifera. The addition of an $800 \mathrm{mg} / \mathrm{L}$ aqueous extract, prepared with $0.5 \%$ in seed weight, lowers the turbidity (20,800 to 80 $N T U$ ) of the pluvial water accumulated in an open pit mining trench. Although the concentrations of sodium, potassium, calcium and magnesium increase considerably with this treatment, the water discharged into the hydrological systems dilutes them so that the actual contents are below the values allowed by Brazilian legislation. The Moringa extract does not mobilize iron from the suspended iron oxide particles, on the contrary of the usual clarification process, which uses a flocculation and a coagulation agent. The use of the extract lowers iron and manganese concentrations in the water, as shown by chemical analyses.
}

Key-words: turbidity, coagulation-flocculation, Moringa oleifera. 